Cites as: Shah DU, 2016, Composites Part A: Applied Science and Manufacturing 83: p.

$160-168$

http://www.sciencedirect.com/science/article/pii/S1359835X15003243

\title{
Damage in biocomposites: Stiffness evolution of aligned plant fibre composites during monotonic and cyclic fatigue loading
}

\author{
Darshil U. Shah \\ Centre for Natural Material Innovation, Dept. of Architecture, University of Cambridge, Cambridge \\ CB2 1PX, UK. \\ E-mail: dus20@cam.ac.uk; darshil.shah@hotmail.co.uk; Tel: +44 (0)1223760124
}

\begin{abstract}
The non-linear stress-strain behaviour of plant fibre composites is well-known in the scientific community. Yet, the important consequences of this, in terms of the evolution of stiffness as a function of applied strain and cycles to failure, are not wellstudied in literature. This is despite the fact that stiffness degradation is a well-accepted indicator of damage in a composite material, and is regularly used as a component failure criterion. This article systematically explores the evolution of stiffness of various aligned plant fibre composites, subjected to $i)$ monotonic loading, ii) low-cycle, repeated progressive loading, and iii) fatigue loading. The evolution in stiffness in plant fibre composites is found to be complex: structural changes in the elementary fibre cell wall and damage development in the composite have often competing effects on stress-strain behaviour. Indeed, the evolution in stiffness of plant fibre composites is found to be unlike that typically observed in traditional composites, and therefore needs to be taken into account in the design of structural components.
\end{abstract}

Keywords: A. Biocomposite; A. Natural fibers; B. Elasticity; C. Damage mechanics; Non-linear behaviour 


\section{Introduction}

Biocomposites have secured a sizeable share $(\sim 10-15 \%)$ of the global fibre reinforced plastics market [1-3]. As current applications are in the automotive industry (viz. interior panels from plant fibre composites), and construction and buildings industry (viz. decking boards from wood plastic composites) [1], both of which are fast-growing markets [2], the uptake of biocomposites is also likely to increase in these lessdemanding applications.

In contrast, while there is still much enthusiasm in the scientific community on the prospects of biocomposites as sustainable solutions for even high-performance applications [3-7], more research on their in-service behaviour and long-term properties is required for reliable performance to warrant industrial acceptance. There is already a small, but growing body of work on important aspects such as the fire-performance [810], long-term fatigue behaviour [11-13], and dynamic behaviour [14, 15] of plant fibre composites.

High-performance components often have multiple failure criteria, some of which require detection prior to 'final failure', especially in the case of fail-safe and faulttolerance design philosophies. For example, in composite wind turbine blade design [16], a functional failure can be judged to have occurred when there is substantial residual deformation (i.e. large tip deflection in the unloaded state), as well as a significant (of the order of $5-10 \%)$ and/or irreversible reduction in stiffness. In fact, noting that stiffness degradation is closely related to crack density, the former is often used as a damage accumulation indicator over the component life $[17,18]$. Both, the stiffness degradation behaviour and the residual stiffness of a material are therefore vital information; the former provides a non-destructive measurement of damage, while the latter informs of the changed ability of the material (through deformation) to endure loads.

Critically, the evolution of stiffness of plant fibre composites (as a function of applied strain and material life, for instance) has not received much attention in literature so far. Note that here I refer to the 'evolution' of stiffness rather than to stiffness 'degradation' as the changes in stiffness over monotonic and cyclic loading of plant fibre composites were found to be complex, and unlike those typically observed for traditional 
fibre reinforced composites. Here, I attempt to draw attention to this knowledge gap, as well as provide experimental data and insights on this topic. In particular, I investigated the evolution of stiffness of aligned plant fibre composites during i) monotonic loading, ii) low-cycle, repeated progressive loading, and iii) fatigue loading. Plant fibre composites comprising of different fibre types (viz. flax, hemp and jute), fibre volume fractions and textile architectures (unidirectional and multi-axial reinforcements) were studied.

\section{Experiments}

\subsection{Materials and manufacture}

For this study, four commercial plant fibre yarns/rovings were used as reinforcements (Table 1). Extensive characterisation of these reinforcement materials is carried out in [19-22]. Unidirectional $\left(0^{\circ}\right)$ mats were prepared from all the four yarns using a drum winding facility and hydroxyethylcellulose binding agent, as described in [19-22]. In addition, unidirectional $\left(0^{\circ}\right)$ and stitched biaxial $\left( \pm 45^{\circ}\right)$ fabrics from the F50 yarn were obtained from Formax UK Ltd. Through comparisons in the properties of composites produced from F50 unidirectional fabrics with and without hydroxyethylcellulose treatment, it has been shown in [21] that the binding agent has no significant effect.

Table 1. Plant fibre material properties.

\begin{tabular}{llllll}
\hline ID & $\begin{array}{l}\text { Fibre } \\
\text { type }\end{array}$ & Spinning company & $\begin{array}{l}\text { Density } \\
{\left[\mathrm{gcm}^{-3}\right]}\end{array}$ & $\begin{array}{l}\text { Linear }^{\dagger} \\
\text { density }^{\dagger}\end{array}$ & $\begin{array}{l}\text { Twist } \\
\text { level }^{\dagger} \\
{[\mathrm{tpm}]}\end{array}$ \\
\hline J190 & Jute & $\begin{array}{l}\text { Janata and Sadat Jute Ltd } \\
\text { (Bangladesh) }\end{array}$ & $1.433 \pm 0.005$ & $206 \pm 21$ & 190 \\
H180 & Hemp & $\begin{array}{l}\text { Safilin } \\
\text { (Poland) }\end{array}$ & $1.531 \pm 0.003$ & $278 \pm 17$ & 180 \\
F50 & Flax & $\begin{array}{l}\text { Composites Evolution } \\
\text { (UK) }\end{array}$ & $1.529 \pm 0.003$ & $229 \pm 22$ & 50 \\
F20 & Flax & $\begin{array}{l}\text { Safilin } \\
\text { (France) }\end{array}$ & $1.574 \pm 0.004$ & $396 \pm 16$ & 20 \\
\hline
\end{tabular}

${ }^{\dagger}$ Measured in [19-22]. 
Composite laminates (250 $\mathrm{mm}$ square, $3.0-3.5 \mathrm{~mm}$ thick) were manufactured via vacuum infusion in a rigid, aluminium mould tool. Resin infusion was carried out at 70$80 \%$ vacuum (200-300 mbar absolute) under ambient temperature. An unsaturated polyester resin (Reichhold Norpol type 420-100) mixed with 0.25 wt $\%$ NL49P accelerator (1\% Cobalt solution) and $1 \mathrm{wt} \%$ Butanox M50 MEKP initiator was used as the matrix. Post cure was carried out at $55^{\circ} \mathrm{C}$ for $6 \mathrm{~h}$ after ambient cure for $16 \mathrm{~h}$.

Laminates with different $i$ ) fibre types (jute (J190), hemp (H180), and flax (F50 and F20) in $[0]_{4}$ layup), ii) fibre volume fractions ([0] $]_{2-5}$ layup of J190 generating four different fibre volume fractions $v_{f}$ in the range of 17-38\%), and iii) textile architectures (F50 in $[0]_{4}$ and $[ \pm 45]_{4}$ layup), were fabricated. The extensive material properties characterisation of these composites can be found in [11, 19, 21-24].

\subsection{Testing}

\subsubsection{Monotonic loading}

Monotonic tensile tests were conducted on unidirectional laminates comprising of different fibre types and fibre volume fractions (described previously). An Instron 5985 testing machine equipped with a $100 \mathrm{kN}$ load cell and a clip-on extensometer was used. $250 \mathrm{~mm}$ long, $10 \mathrm{~mm}$ wide specimens were tested for each type of composite at a crosshead speed of $2 \mathrm{~mm} / \mathrm{min}$.

From the stress-strain curve (Fig. 1), the initial elastic modulus $E_{0}$ was determined from the initial tangent modulus in the strain range of $0.025-0.100 \%$, as prescribed in literature given the low elastic limit (of around $0.10-0.15 \%$ ) of plant fibre composites [23, 25-27]. The residual or apparent stiffness $E$ at $\varepsilon \%$ strain was thereafter calculated using the tangent modulus at $\varepsilon \%$ strain (Fig. 1).

\subsubsection{Progressive cyclic loading}

Unidirectional $\left(0^{\circ}\right) \mathrm{F} 50$ composites (based on the mats supplied by Formax UK Ltd) were tested under a repeated progressive loading regime in an Instron 5985 testing machine equipped with a $100 \mathrm{kN}$ load cell and a clip-on extensometer. $250 \mathrm{~mm}$ long, 10 $\mathrm{mm}$ wide specimens were tested. Specimens were subjected to successively larger loading-unloading cycles (to $700 \mathrm{~N}, 1350 \mathrm{~N}, 1900 \mathrm{~N}, 2350 \mathrm{~N}, 2800 \mathrm{~N}$, and to failure) at a 
load/unload rate of $7000 \mathrm{~N} / \mathrm{min}$. The loading rate used ensured specimen failure (in the last cycle to failure) in around 40-60 seconds, which was comparable to the time to failure for monotonic loaded specimen (at the previously used extension rate of 2 $\mathrm{mm} / \mathrm{min})$. The test procedure is described in more detail in $[21,23]$.

From the stress-strain curve (Fig. 2), the initial elastic modulus $E_{0}$ was determined in the very first loading cycle from the initial tangent modulus in the strain range of $0.025-0.100 \%$. The residual or apparent stiffness $E$ at $\varepsilon \%$ strain was thereafter calculated using the tangent modulus at $\varepsilon \%$ strain for all loading cycles (Fig. 2).

\subsubsection{Cyclic fatigue loading}

Fatigue tests were conducted on an Instron 8801 servo-hydraulic testing machine under load-control mode. Constant amplitude loads were applied in a sinusoidal waveform at a frequency of $10 \mathrm{~Hz}$. In accordance with BS ISO 13003:2003 [28], at least five specimens were tested to failure at a minimum of five levels of stress (eg. 90\%, 80\%, $70 \%, 60 \%$, and $50 \%$ of ultimate strength $\sigma_{f}$ ), up to at least $10^{6}$ cycles, for the determination of the material stress-lifetime diagram. All manufactured composites (i.e. different fibre types, different fibre volume fractions and different textile architectures, as described earlier) were tested in tension-tension mode (at a stress ratio of $R=0.1$ ). In addition, to study the effect of stress ratio, hemp H180 composites were studied under five different stress ratios: $R=0.1,0.3,0.5$ in tension-tension mode, $R=-1$ in tensioncompression mode, and $R=2.5$ in compression-compression mode. Further details on specimen preparation and the test procedure can be found in $[11,21]$.

To specifically study the evolution of stiffness as a function of the materials fatigue life $n / N_{f}$ (where $n$ is the number of cycles faced and $N_{f}$ is the failure life), the stiffness of the specimen was determined from the load-extension curve, as done by other researchers studying plant fibre composites $[12,29]$, using strain measurement directly from cross-head displacement. The initial stiffness $E_{0}$ was determined from the first entire loading curve (Fig. 3). The residual stiffness $E$ at $n$ cycles was thereafter determined using the peak-to-peak values from the entire loading/unloading cycle loop (Fig. 3), as done by other researchers $[12,29]$. 


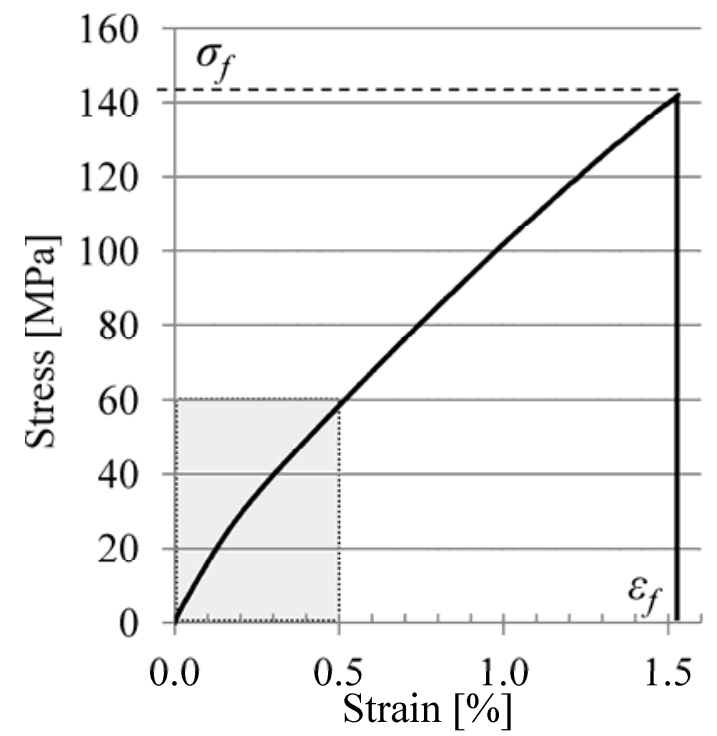

a)

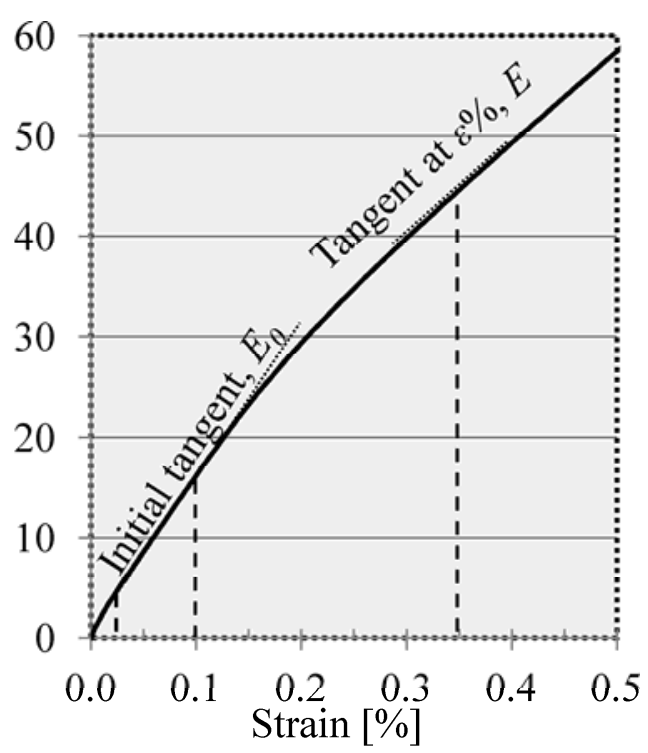

b)

Fig. 1. The initial stiffness $E_{0}$ and residual stiffness $E$ were extracted from the material tensile stress-strain curve (a). The elastic Young's modulus $E_{0}$ was determined using the initial tangent modulus in the strain range of $0.025-0.100 \%$ (b). The residual or apparent stiffness at $\varepsilon \%$ strain was determined using the slope of the tangent at $\varepsilon \%$ strain.

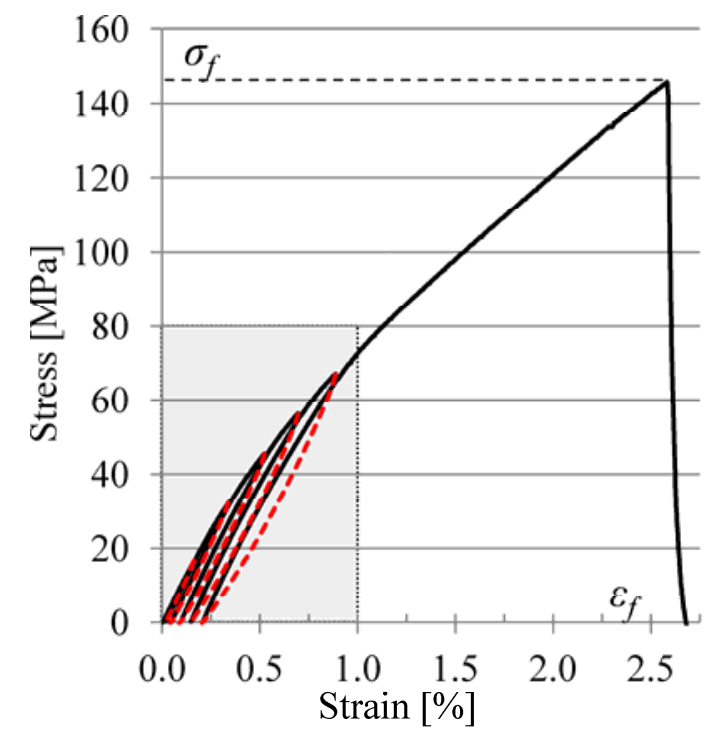

a)

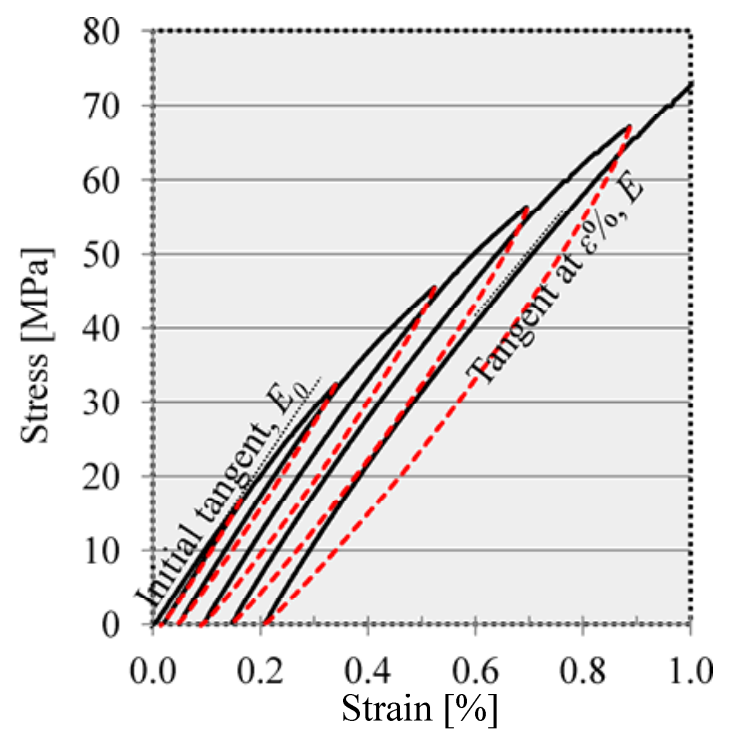

b)

Fig. 2. a) Unidirectional flax composites were subjected to repeated progressive loading. Solid black lines indicate loading, while dashed red lines indicate unloading. b) From the stress-strain response of the material, the elastic Young's modulus $E_{0}$ was determined using the initial tangent modulus in the strain range of $0.025-0.100 \%$ for the very first loading cycle. The residual stiffness $\mathrm{E}$ at $\varepsilon \%$ strain was determined using the slope of the tangent at $\varepsilon \%$ strain for all loading cycles. 


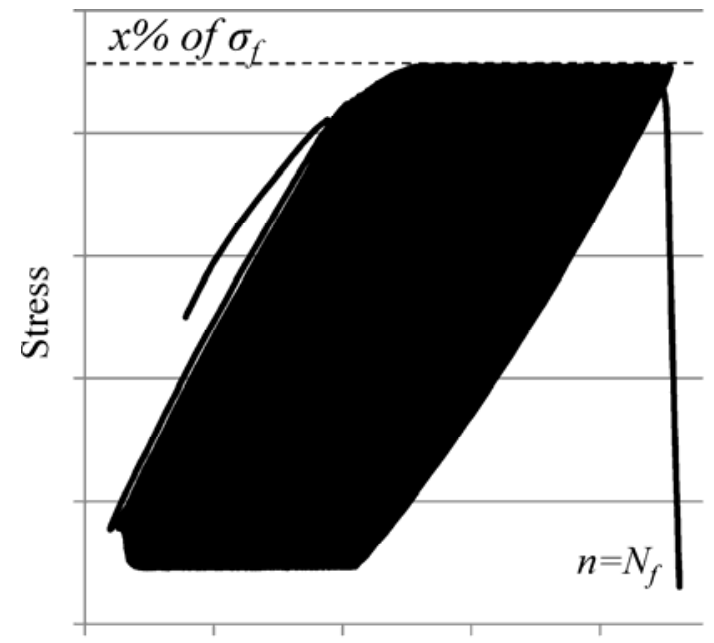

Strain

a)

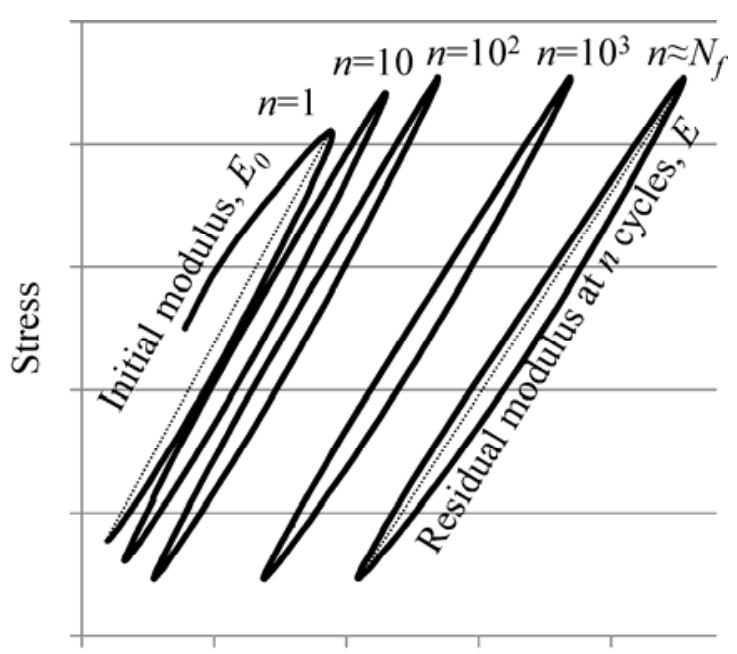

Strain

b)

Fig. 3. a) Stress-strain profile of plant fibre composite subjected to fatigue loading. b) The elastic Young's modulus $E_{0}$ was determined using the peak-to-peak values of the first loading-unloading cycle. The residual stiffness $E$ at $n$ cycles was determined using the peak-to-peak values from the loading/unloading loop at $n$ cycles. Failure occurs at $n=N_{f}$.

\section{$3 \quad$ Results and Discussion}

\subsection{Stiffness degradation during monotonic loading}

The evolution of normalised residual stiffness $E / E_{0}$ as a function of applied strain for the various unidirectional plant fibre composites is presented in Fig. 4. It was observed that the stiffness variation in all the plant fibre composites, irrespective of fibre/yarn type and fibre volume fraction, could be separated into two regions. In the first region, a dramatic reduction in stiffness, of the order of $30-50 \%$ of their initial stiffness, was observed up to an applied strain of $0.4 \%$. Thereafter, in general, the stiffness remained fairly constant up to their failure strain (ranging from 1.2-1.7\%), if not increasing or decreasing marginally. This has also been observed in few other studies on plant fibre composites $[23,25,26,30]$, including testing the effect of off-axis loading of unidirectional laminates [23], and the effect of twisted yarns and un-twisted rovings as reinforcements [25].

Before discussing the possible sources of this non-linearity and consequent stiffness reduction phenomenon in the stress-strain behaviour of these plant fibre composites, two important issues need to be raised regarding component design using 
plant fibre composites. Firstly, such a large drop in stiffness even at low applied strains suggests that perhaps the initial stiffness $E_{0}$ is not an appropriate indicator of the 'practical stiffness' (i.e. value to be used for component design) of plant fibre composites. Indeed, if a component were to be designed using the initial stiffness $E_{0}$, and were subjected to low stresses above the yield point, the subsequent reduction in stiffness of up to $50 \%$ may raise issues of not only tolerance, but also immediately flag-up as a functional failure (at least in wind turbine blades, as per [16]) as the component may not be able to fulfil its function, or function within acceptable limits. Rather, the fairly stabilised residual stiffness (above $0.4 \%$ applied strain) may be a more appropriate design value. Ideally, perhaps researchers should routinely report both the initial stiffness (in the strain range of $0.025-0.100 \%$, below the yield point) and the residual stabilised stiffness (above $0.4 \%$ applied strain) of plant fibre composites.

Secondly, the strong (at least initially) non-linear behaviour of plant fibre composites was in stark contrast to the linear behaviour of conventional E-glass composites, where the latter exhibited a reduction in stiffness of only $3 \%$ up to an applied strain of $0.4 \%$, and a reduction in stiffness of up to $10-15 \%$ at the vicinity of failure (Fig. 4a). In addition, while the stiffness reduction in plant fibre composites was initially drastic and thereafter stabilised, glass composites exhibited a gradual, linear decrease in stiffness as applied strain was increased (Fig. 4a). This difference in stress-strain behaviour of plant fibre composites and glass fibre composites has been reported earlier, both in coupon tests $[23,26,27]$ as well as in large-scale components (such as wind turbine blade case studies) [4]. A difference in damage accumulation mechanisms has been suggested for natural fibre and synthetic fibre reinforced composites. Plant fibre composites, due to their weak(er) fibre-matrix interface, are suggested to demonstrate fibre/matrix debonding and interface failure, while the prevailing damage mechanism in glass fibre composites is suggested to be matrix transverse cracking [26]. In addition, unlike glass fibres which are isotropic, homogenous materials and display linear-elastic behaviour, plant fibres are natural materials which have inhomogeneous properties, natural defects (such as kink bands), and are intrinsically non-linear materials [23, 26, 27]. 

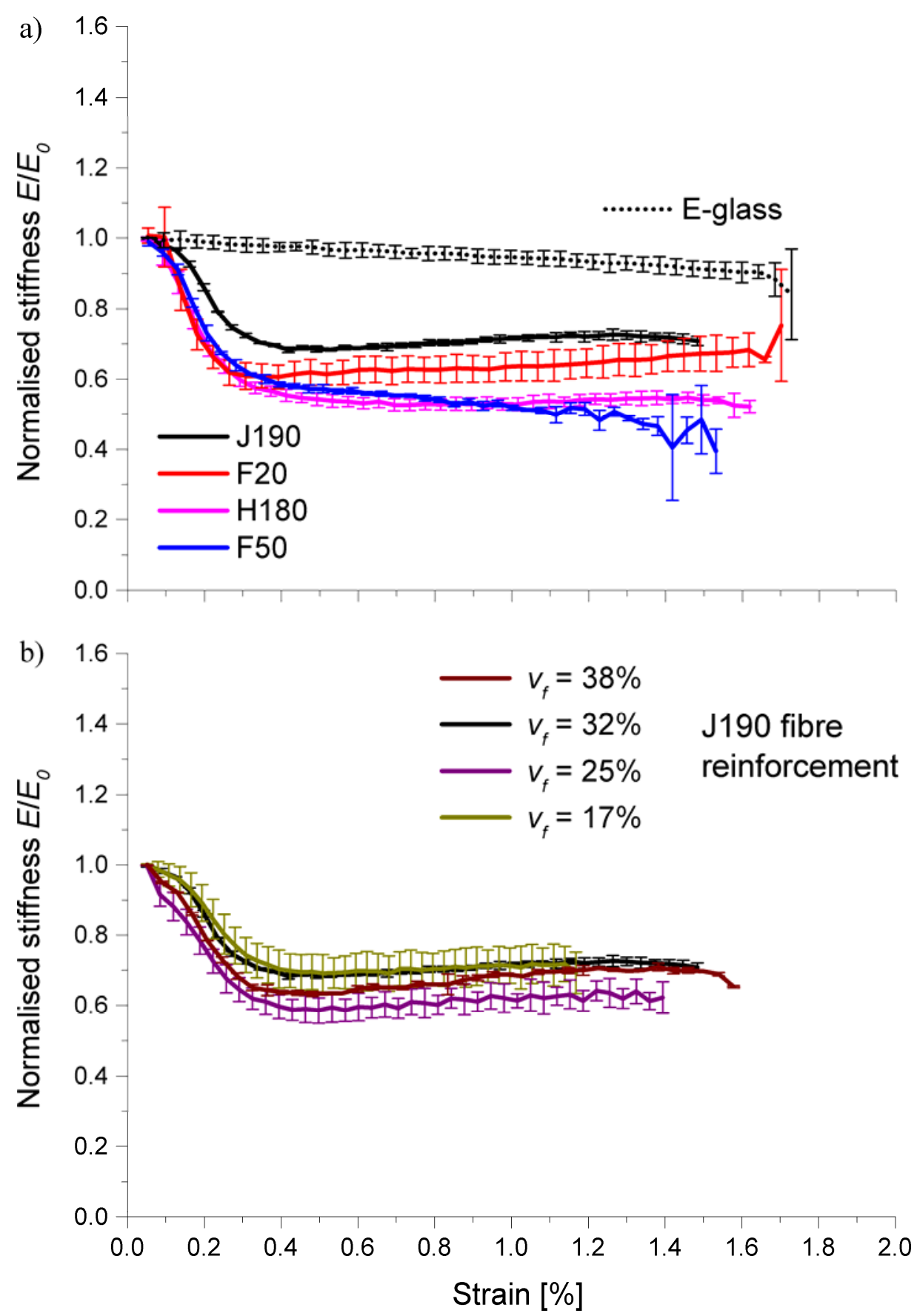

Fig. 4. Stiffness variation as a function of applied strain on monotonic tensile loaded unidirectional laminates: (a) effect of fibre type, and (b) effect of fibre volume fraction. Residual stiffness $E$ has been normalised by the initial stiffness $E_{0}$. The data for unidirectional E-glass/polyester laminate in (a) is from [21, 23]. Error bars indicate one standard deviation. 


\subsubsection{Possible origins of the stiffness degradation}

Even at low levels of stress in monotonic loading, composites may sustain damage [31]. In the case of plant fibre composites, including the ones that have been tested in this study, it has been previously shown [23, 25-27] that their elastic limit (or yield strain) is of the order $0.10-0.15 \%$. Applied strains above this elastic limit do lead to some irreversible plastic deformation [21, 23]. As this damage is likely to be distributed across the stressed region, it may reduce stiffness [31].

The source of the non-linear stress-strain behaviour (and the low yield strain) of plant fibre composites were initially conjectured in literature to derive from two different scales [23, 25, 30]: a) from the macro-scale reinforcement (viz. twist in a yarn, and offaxis rovings), and $b$ ) from the plant fibre itself.

There are contradictory reports on the influence of yarn twist on the non-linear behaviour of plant fibre composites. Li and Yuan [32] find that the stress-strain profile of twisted yarn reinforced sisal fibre composites is non-linear, while that of un-twisted counterparts is linear. In contrast, both Shah et al. [23] and Baets et al. [25] find that plant fibre composites based on even un-twisted yarns and rovings exhibit a strong non-linear behaviour; as observed in this study for F20 and F50 composites (Fig. 4a). It is conceivable, perhaps, that just like twisted and untwisted single plant fibres [33], composites based on twisted yarns may exhibit a pronounced non-linear behaviour in comparison to un-twisted roving based composites. However, even if the mis-orientations from yarn twist and off-axis rovings were to affect stiffness, they should initially increase stiffness (rather than decrease stiffness) due to the reorientation of the misaligned yarns/fibres in the loading axis.

Given the well-reported non-linear stress-strain behaviour of elementary plant fibres themselves (e.g. [33-38]), there is a much stronger case that they are the source of the non-linearity in the composites. Notably, acoustic emissions analyses [26, 27] conducted on unidirectional flax composites to probe their damage mechanisms find that while low-amplitude $(<20 \mathrm{~dB})$ acoustic emission events do occur at the vicinity of the yield strain (between 0.1-0.2\%) [27], the damage threshold strain is much higher (at least two times higher) than the yield strain [26]. While the former implies that some 
microstructural failure events (e.g. interface failure and debonding facilitated by stressconcentration at kink bands, and transverse cracking in the matrix [27]) may have initiated in the composite at even $0.1 \%$ strain, the latter suggests non-linearity in the composite stress-strain curve and associated stiffness degradation is caused by intrinsic changes in stiffness (and non-linear behaviour) of the plant fibre itself, even in the absence of damage (in the matrix or interface) in the composite [26]. Andersons et al. [30] have also alluded to this in modelling the stress-strain behaviour of unidirectional plant fibre composites. Essentially, non-linearity in stress-strain response is an intrinsic characteristic of plant fibres, which transfers into the reinforced composite.

To examine this further, Fig. 5 compares the tensile stress-strain behaviour and stiffness evolution in a typical elementary plant fibre (F20 fibre) and plant fibre composite (F20/polyester), by normalising the stress, strain and stiffness by their respective failure stress, failure strain and initial stiffness.

The stress-strain response of the plant fibre shown is similar to that found by other scientists $[33,37,39,40]$. Fig. 5b) clearly shows that both the fibre and the composite exhibit an initial reduction in stiffness, albeit the stiffness decrease was more gradual and to a lesser extent in the fibre. The stiffness decrease in the fibre is attributed to the yielding and viscous flow of the lignin-hemicellulose matrix and amorphous cellulose, due to shear stress in the cell wall [33]. However, thereafter, while the stiffness remains fairly stable in the composite, the stiffness of the fibre recovers, and in fact exceeds the initial stiffness by up to $20 \%$. The increase in stiffness in the fibre is attributed to the significant, (partly-)irreversible reorientation of cellulose microfibrils in dislocation areas (viz. kink bands), but also to the spiral spring-like extension of cellulose microfibrils and shear-stress induced crystallisation of the amorphous cellulose [33]. In particular, the reorientation of cellulosic microfibrils is driven through a 'stick-slip mechanism' where the cellulose microfibrils slide past each other in the shear-deformed lignin-hemicellulose matrix through a process of continuous breakage and reformation of hydrogen bonds between fibril-fibril and fibril-matrix, and continuous stripping of cellulose-bridging hemicellulose chains [26, 33, 35-37, 39]. Other researchers have also suggested that defects (such as kink bands) and damage to the cell wall (such as by cell wall buckling) may contribute to the general non-linear behaviour of plant fibres [27, 33, 41]. 
The recovery in stiffness that is observed in the fibre (beyond $0.4 \%$ applied strain) is not observed in the composite, possibly because microstructural failure events in the composite (e.g. matrix failure and fibre/matrix interface failure) may have started occurring by then, as suggested from damage threshold strain measurements through acoustic emission testing [26]. Fibre/matrix debonding, for instance, would not enable efficient stress-transfer from the matrix to the fibre; consequently, perhaps not all the fibres will be strained to experience the spiral spring-like extension of microfibrils and the strain-induced crystallisation of the cellulose (i.e. important stiffening mechanisms in the fibre). There would be therefore some averaging effect in the composite. In addition, mis-orientations in the macro-structure (e.g. misalignment/waviness in rovings, twist/crimp in yarn) may also contribute (also through an averaging effect) in the composite.

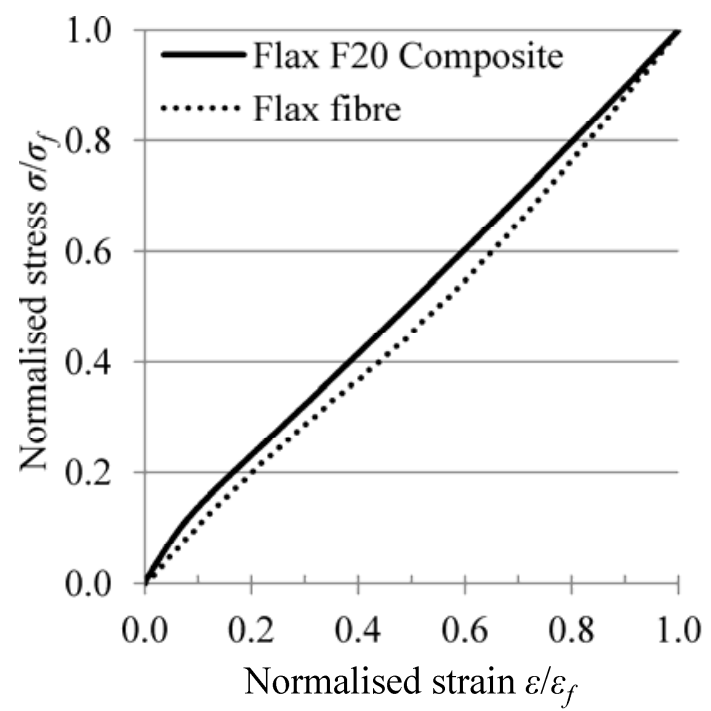

a)

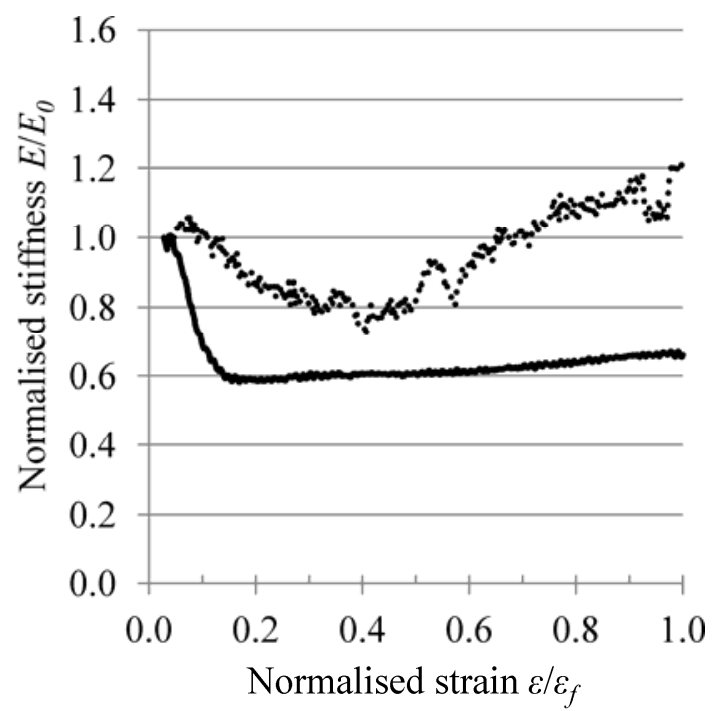

b)

Fig. 5. Comparison of tensile stress-strain development (a) and stiffness variation (b) in a single F20 flax fibre (dotted line; data from [21, 24]) and in a unidirectional flax F20/polyester composite (solid line).

\subsection{Stiffness evolution during repeated progressive loading}

Repeated progressive loading of unidirectional flax F50/polyester composites has been previously used to ascertain the yield point of these materials at $\sim 0.15 \%$ and to examine plastic strain development [23]. Here, that data has been reprocessed to examine stiffness variation. Fig. 6 plots the change in stiffness in all loading cycles (normalised to 
the initial stiffness at the first loading cycle), and compares it to the behaviour of the monotonic tensile-loaded material.

Several initial observations were made. First, with every loading cycle, a characteristic drop in composite stiffness was observed, as also noticed in monotonic loading tests (Section 3.1). Second, the plastic strain was observed to increase with every successive, increased loading cycle, as described in [23]. This indicates some permanent damage. Third, despite this damage, immediately upon reloading, the residual stiffness was observed to return to and even increase $15-20 \%$ beyond the original stiffness $E_{0}$. This may be explained by the previously described stick-slip mechanism, wherein an initial 'activation energy' (corresponding to a stiffness) is required to initiate deformation, and thereafter it becomes easier and easier to deform the material (decreasing stiffness). Fourth, reloading the samples led to a drop in stiffness (with increased applied strain) similar to the previous cycle, suggesting that the mechanisms leading to stiffness reduction are similar even after repeated loading/unloading cycles. Finally, it was observed that the drop in stiffness at the end of every loading cycle was similar to the drop in stiffness at that same applied strain in a monotonic tensile loaded sample. Indeed, both the repeated progressive loaded and monotonic loaded samples exhibited a stabilised ratio of residual stiffness to initial stiffness of around $50 \%$. This indicates that the stiffness-degradation behaviour may be highly strain-controlled in plant fibre composites. This is particularly noteworthy because Virk et al. [42] have proposed failure strain as a key design criterion for the fracture of plant fibre composites.

Two differences were also observed in stiffness evolutions of monotonic and progressive cyclic loaded samples. Firstly, the residual stiffness stabilised after $\sim 0.4 \%$ applied strain in the monotonic loaded samples, but stabilised in the progressive cyclic loaded samples only after $\sim 1.2 \%$ applied strain. This would partly be due to residual strain accumulation in cyclic loaded samples, and the stick-slip mechanism proposed earlier which shifts the stiffness stabilisation point to higher applied strains. Secondly, the shape of the stiffness degradation curves was different. The stiffness evolution in monotonic loaded samples exhibited two distinct regions of initial drastic stiffness reduction and thereafter stabilisation, as explained in Section 3.1. In contrast, progressive cyclic loaded samples, at least from the third cycle onwards, showed three distinct 
regions: i) an initial moderate decrease followed by ii) a knee in the curve (inflection point) after which the stiffness degraded at a faster rate, only to iii) stabilise in the final cycle beyond an applied strain of $\sim 1.2 \%$. Notably, the knee, just like the residual plastic strain, shifted to the right (i.e. towards increasing applied strain) with every progressive cycle, almost exactly to the maximum applied strain of the previous loading cycle. The knee is therefore an indicator of current state of damage, where 'lock-in' may occur at the new position; strains applied beyond the strain at the knee leads to further damage and accelerated stiffness degradation.

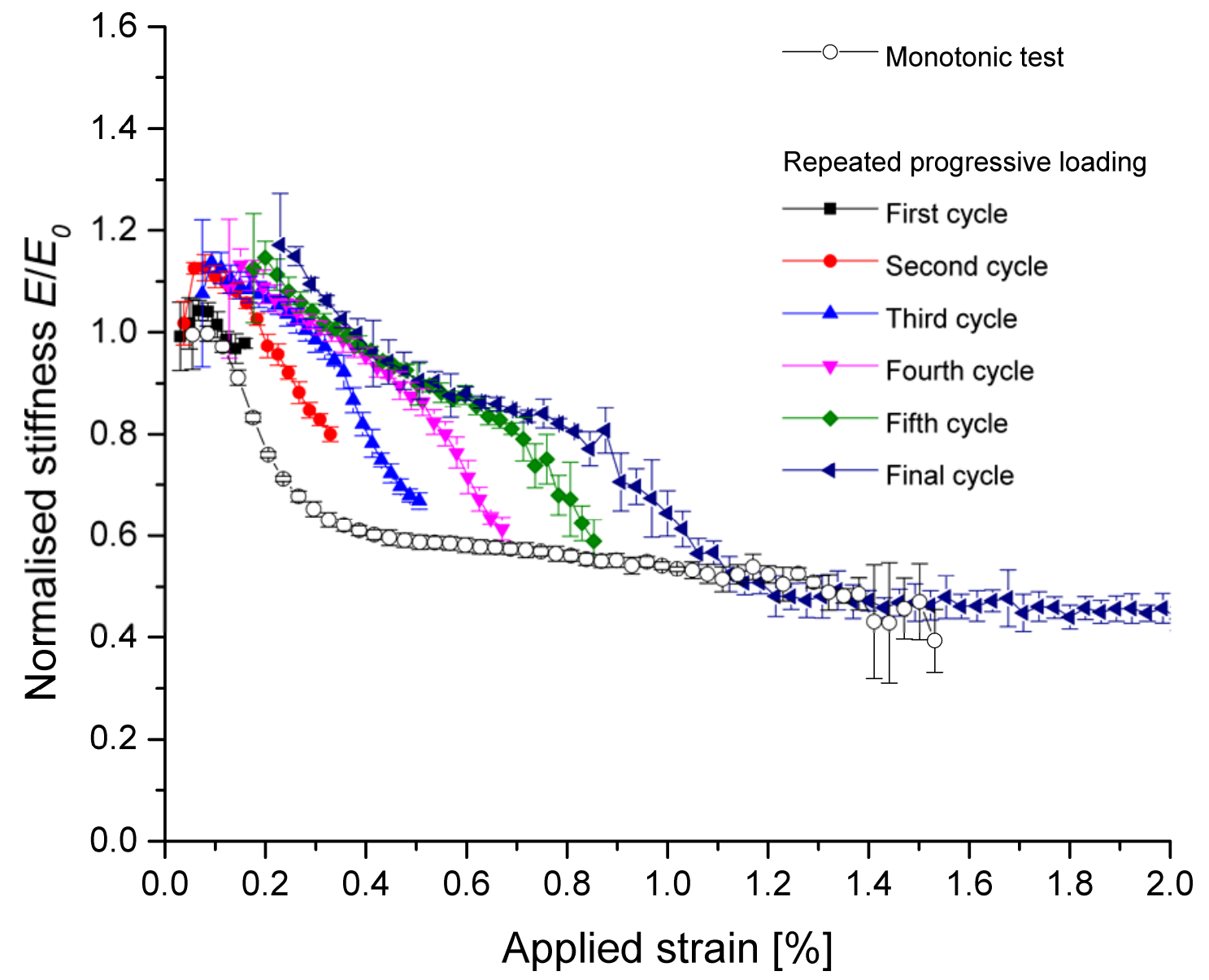

Fig. 6. Stiffness variation as a function of applied strain on unidirectional F50 composites subjected to repeated progressive loading (filled dots). The residual stiffness $E$ in each loading cycle is normalised by the initial stiffness $E_{0}$ in the first loading cycle. For comparison, the stiffness variation in unidirectional F50 composites subjected to monotonic tensile loading is also presented (unfilled dots). Error bars indicate one standard deviation. 


\subsubsection{Comparisons with single plant fibres}

Placet et al. [33] have provided an expert hypothesis on the non-linear behaviour of elementary hemp fibres that are subjected to repeated progressive loading (based on observations and explanations from several studies (including [35-37, 40, 43-46]), backed by their own experimental assessment). Their observations on single fibres tie up well with the observations on the composites studied here.

Their hemp fibres show higher stiffness (relative to the initial stiffness in the first cycle) immediately upon reloading after unloading; this is attributed to irreversible stiffening of the fibre from the previous loading cycle due to strain-induced crystallisation of amorphous cellulose, partially irreversible re-orientation of cellulose microfibrils in the loading axis, and spiral spring-like extension of cellulose microfibrils [33]. Interestingly, they observe that immediately upon reloading after every load-unload cycle, the stiffness of fibres increased linearly by up to 4 fold (relative to initial stiffness) as a function of strain. In contrast, we observed the stiffness of our composite to increase by only $15-20 \%$. Placet et al. [33] also find that both residual plastic strain development and stiffness increase (upon immediately re-loading) had a time-dependent response, with increasing dwell-times between loading-unloading cycles leading to some recovery in residual plastic strain and a reduced stiffness increase of only up to 2 folds (relative to initial stiffness). The lower increase in stiffness of the composites may be due to an averaging effect (e.g. not all fibres may have been strained in the previous cycle, and therefore fibre stiffening mechanisms may not have occurred in all fibres). Once the strain increases above the yield strain in the plant fibre (of the order of $0.1-0.2 \%[33,37]$, similar to plant fibre composites studied here), a reduction in stiffness occurs, as is observed in the composites studied here, due to shear-induced viscous flow of amorphous polymers in the fibre cell wall and the stick-slip mechanism described previously for monotonic tensile loading [44]. When the strain is removed, Placet et al. [33], as per Keckes et al. [44], suggest that a lock-in occurs (because there is no 'back-flow' of the matrix) where bonds immediately reform between the matrix and the cellulose fibrils in the new position. This stick-slip mechanism and locking-in phenomenon also leads to substantial plastic strain development without causing significant damage (in the ligninhemicellulose matrix and between the fibril-matrix interface). This enables the stiffness 
to recover upon re-loading. The proposed stress-strain mechanism of the fibres corroborates with the behaviour of the composites observed previously.

\subsection{Stiffness evolution during fatigue loading}

The fatigue behaviour of the various plant fibre composites manufactured was assessed elsewhere [11], in the form of stress-lifetime diagrams and constant-life diagrams. Here, the raw data was re-analysed to examine stiffness evolution over the material fatigue life (Fig. 7). Note that no clear trend was observed on the effect of loading level (i.e. \% load of ultimate strength $\sigma_{f}$ ) in stiffness evolution.

From Fig. 7a), it is evident that near failure $\left(n / N_{f} \sim 0.95\right)$ unidirectional plant fibre composites show a change in stiffness (relative to the initial stiffness) in the range of $10 \%$ to $+5 \%$. The jute and hemp composites show almost no change ( $\pm 2-3 \%)$ in stiffness with fatigue life, similar to high performance unidirectional carbon fibre composites [18]. While flax F20 composites show an increase in stiffness of up to 5\% (majority of it early in their fatigue life), flax F50 composites show a decrease in stiffness of around 10\% (linearly over their fatigue life). The flax F50 yarn employs an S-twist polyester binder yarn (13wt\%) [23]; while the core flax yarns have a mean twist angle of only $3^{\circ}$, the untwisting in the binder yarn may have led to this stiffness reduction in the composite. Fig. 7b) reveals that even jute composites, at varying fibre contents, show a stiffness reduction of up to $10 \%$ over their fatigue life, although there is no clear correlation between fibre content and stiffness reduction. In the case of jute composites, however, majority of the stiffness decrease is in the early part of their fatigue life.

In typical unidirectional glass and graphite laminates, often an initial increase in stiffness (up to $E / E_{0} \approx 1.2$ ) is observed, attributed to the realignment of off-axis $0^{\circ}$ tows, and thereafter a reduction in stiffness occurs (up to $\left.E / E_{0} \approx 0.6\right)$ near failure $\left(n / N_{f} \sim 0.90\right.$ ) [18]. Comparing this to the results on the plant fibre composites, firstly, the stiffness reduction (if any) is found to be to a lower magnitude in plant fibre composites; this has also been demonstrated by Liang et al. [12, 29] for various textile architectures. In addition, the behaviour of the plant fibre composites is different from that of conventional fibre reinforced composites, in terms of general trends in stiffness evolution over fatigue life. Therefore, conventional damage evaluation models in fatigue (e.g. normalised 
stiffness degradation models [18]) may require some modifications to be applicable to plant fibre composites.

The effect of textile architecture on stiffness evolution is shown in Fig. 7d), where biaxial flax composites show a stiffness reduction of $50 \%$ at the end of their fatigue life, which is in contrast to the $10 \%$ reduction in stiffness of unidirectional flax composites. This effect is also observed in conventional composites; off-axis plies have more matrixdominated stressed regions which undergo matrix cracking. This alongside visco-elastic creep in the matrix dominated regions result in a more pronounced reduction in stiffness from the very beginning of fatigue loading (unlike the initial increase in stiffness observed in unidirectional synthetic fibre composites) [18].
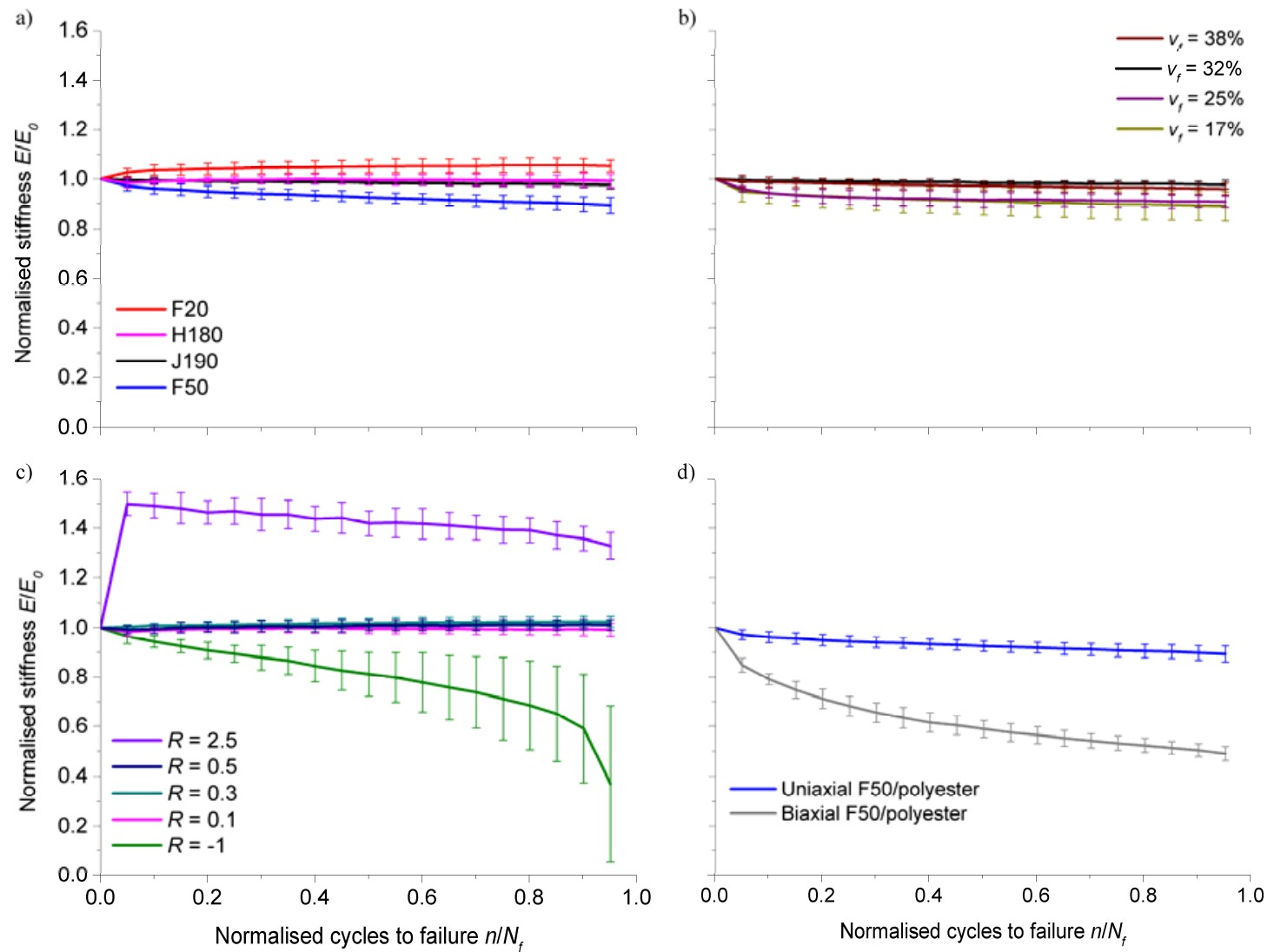

Fig. 7. Stiffness variation as a function of fatigue life $\left(n / N_{f}\right)$ for various plant fibre composites. The effects of fibre/yarn type in unidirectional composites (a), effect of fibre volume fraction in unidirectional jute J190 composites (b), the effect of applied stress ratios for hemp H180 unidirectional composites (c) and the effect of textile architecture for flax F50 composites, are presented. The residual stiffness $E$ in each loading-unloading 
cycle is normalised by the initial stiffness $E_{0}$ in the first loading-unloading cycle. Error bars indicate one standard deviation.

\subsubsection{Comparisons with single plant fibres}

Baley [40] and Silva et al. [47] have previously investigated the stiffness evolution in elementary flax fibres and technical sisal fibre bundles, respectively, subjected to cyclic fatigue loading. Baley find that the stiffness of a flax fibre in the last few cycles before failure ( 200 cycles) is $60-80 \%$ higher relative to the initial stiffness [40]. As before, the increase in stiffness is attributed to internal structural changes, specifically the progressive reorientation of cellulose fibrils and spiral spring-like extension of the fibrils. As the large part of the increase in stiffness occurs in the very first few $(\sim 10)$ cycles [40], and as stiffness increase is higher at higher stresses [40, 47], this indicates that the structural changes occur more readily early on and at higher stresses (although the latter would be expected). No drop in stiffness is observed at cycles near the breaking of the fibre [40].

While the stiffness increase during the fatigue loading of unidirectional flax composites has been previously explained by the re-orientation of cellulose microfibrils $[12,29]$, it is notable that the stiffness increase is not always observed (viz. jute, hemp and flax F50 composites in Fig. 7a)), and even if there is a stiffness increase, it is only an increase by up to $10 \%$. The former suggests that there are competing mechanisms in the fatigue degradation of plant fibre composites, probably between a stiffness increase expected from structural changes in the cell walls described previously and realignment of off-axis yarns/rovings, and a stiffness decrease expected due to damage development through visco-elastic creep and shear deformation in the matrix (both the extracellular polyester matrix, and the intracellular lignin-hemicellulose matrix) and matrix/interface cracking. These, alongside any averaging effects (e.g. from unstrained fibres which are not straight or are not well-bonded to the matrix), may also explain why the stiffness changes are moderate, if any, in the composite, but much larger in the single fibre.

\subsubsection{Effect of stress ratio}

Changing the stress ratio from tensile-tensile $(R=0.1,0.3,0.5)$ to tensilecompressive $(R=-1)$ to compressive-compressive $(R=2.5)$ had a notable effect on 
stiffness evolution trends with fatigue life (Fig. 7c)). While tensile-tensile loading had an insignificant effect on the residual stiffness of the composites $\left(E / E_{0} \approx 0.99-1.02\right.$ at $n / N_{f} \sim$ $0.95)$, tensile-compressive loading drastically reduced the residual stiffness to $<40 \%$ at $n / N_{f} \sim 0.95$ but compressive-compressive loading substantially increased the residual stiffness by $40-50 \%$ of the initial stiffness over its fatigue life.

Notably, constantly life diagrams have shown that the unidirectional hemp H180 composites perform best under compressive-compressive loading, and worst under tensile-compressive loading [11]. As both compressive-compressive loaded and tensilecompressive loaded samples fail principally in Mode II (in-plane shear mode) with kink formation [11], the final failure mechanism does not provide an explanation. One would expect perhaps, that compressive-compressive loads would result in an increase in misalignment of the microfibrils to the loading axis, and thereby decrease stiffness. The influence of compressive-compressive and tensile-compressive loads on the fatigue behaviour, and more so the microstructure, of single plant fibres needs to be studied, possibly through repeated loading loop tests (e.g. [48]). In fact, in general, the compressive behaviour of natural fibres and their composites needs to be better understood, as although plant fibres have been shown to have higher compressive strengths and indeed higher ratios between tensile to compressive strength (of around $80 \%$ ) than conventional high performance polymer fibres, plant fibre composites do not perform well under monotonic compressive loads, due to the presence of kink bands in the fibres $[21,49]$.

\section{Conclusions}

This experimental investigation revealed the complex variations in stiffness as a function of applied strain or failure life of various aligned plant fibre composites that were subjected to a range of loading regimes, namely i) monotonic, ii) repeated progressive, and iii) fatigue. The findings contribute to the better understanding of a) the in-service behaviour of biocomposite materials that are aimed towards structural applications, and b) how the complex behaviour of plant fibres translates into their composites. 
From monotonic tests, it was found that the stiffness of plant fibre composites dropped substantially (up to 50\%) at low applied strains $(<0.4 \%$ ), thereafter stabilising. Such a reduction is unique to these plant fibre composites and is not observed in traditional fibre reinforced plastics. The initial stiffness, therefore, may not be an appropriate stiffness value to be used in component design or materials selection (based on materials selection charts [50], for instance). Interestingly, progressive cyclic loading studies find that the reduction in stiffness is reversible, and in fact the initial stiffness is recovered and even exceeded (by up to $20 \%$ ) when the strain is released. Moreover, upon re-loading (after repeated loading-unloading cycles), the same stiffness degradation behaviour is observed, with a stabilised stiffness value similar to that observed in monotonic loading. Therefore, it is suggested that researchers and materials engineers ought to report both the initial stiffness (below the yield strain of $0.10-0.15 \%$ ) and the stabilised stiffness (above an applied strain of $0.4 \%$ ) of plant fibre composites. Fatigue tests revealed that the stiffness change over the fatigue life in plant fibre composites is lower in magnitude than that observed in glass fibre composites.

The study confirms that the complex, non-linear behaviour of single plant fibres translates into their reinforced composites, and any differences can be explained through the competing damage development mechanisms and in the composite.

\section{Data accessibility}

The datasets supporting this article and used to produce Fig. 4 to 7 will be made available on Cambridge University's data repository [https://www.repository.cam.ac.uk/].

\section{Acknowledgements}

The dataset used in this study is based on experimental work carried out by myself at the University of Nottingham and supported by the Nottingham Innovative Manufacturing Research Centre (courtesy: Dr Peter Schubel) between 2011-2012. During the data analysis and write-up of this work at the University of Cambridge, I have been supported by a Leverhulme Trust Programme Grant (courtesy: Michael Ramage). I am grateful to Prof Ignaas Verpoest and his team at KU Leuven for insightful discussions on 
the non-linearity phenomena in plant fibre composites. I also thank the anonymous referees for suggesting valuable improvements to this manuscript.

\section{References}

1. Carus, M., Eder A, Dammer L, Korte H, Scholz L, Essel R, Breitmayer E, Wood-plastic composites (WPC) and natural fibre composites (NFC): European and global Markets 2012 and future trends, in WPC/NFC Market Study 2014-03. 2014, nova-Institut GmbH: Hürth, Germany.

2. Reux, F. Worldwide composites market: Main trends of the composites industry. in 5th Innovative Composites Summit - JEC ASIA 2012. 26-28 June 2012. Singapore.

3. Shah, D., Developing plant fibre composites for structural applications by optimising composite parameters: a critical review. Journal of Materials Science, 2013. 48(18): p. 6083-6107.

4. Shah, D., Schubel PJ, Clifford MJ, Can flax replace E-glass in structural composites? A small wind turbine blade case study. Composites Part B: Engineering, 2013. 52: p. 172-181.

5. Sharma, B., Gatoo A, Bock M, Ramage M, Engineered bamboo for structural applications. Construction and Building Materials, 2015. 81: p. 66-73.

6. Miao, M., Finn N, Conversion of natural fibres into structural composites. Journal of Textile Engineering, 2008. 54(6): p. 165-177.

7. Goutianos, S., Peijs T, Nystrom B, Skrifvars M, Textile reinforcements based on aligned flax fibres for structural composites, in Composites Innovation 2007 - Improved sustainability and environmental performance. 2007: Barcelona, Spain.

8. Crossley, R., Schubel PJ, Stevenson A, Furan matrix and flax fibre as a sustainable renewable composite: Mechanical and fire-resistant properties in comparison to phenol, epoxy and polyester. Journal of Reinforced Plastics and Composites, 2014. 33(1): p. 58-68.

9. Kozłowskiy, R., Władyka-Przybylak M, Flammability and fire resistance of composites reinforced by natural fibres. Polymers for Advanced Technologies, 2008. 19: p. 446-453.

10. Chapple, S., Anandjiwala R, Flammability of natural fiber-reinforced composites and strategies for fire retardancy: A review. Journal of Thermoplastic Composite Materials, 2010. 23(6): p. 871893.

11. Shah, D., Schubel PJ, Clifford MJ, Licence P, Fatigue life evaluation of aligned plant fibre composites through $S$ - $N$ curves and constant-life diagrams. Composites Science and Technology, 2013. 74: p. 139-149.

12. Liang, S., Gning PB, Guillaumat L, Properties evolution of flax/epoxy composites under fatigue loading. International Journal of Fatigue, 2014. 63: p. 36-45.

13. Towo, A., Ansell MP, Fatigue of sisal fibre reinforced composites: Constant-life diagrams and hysteresis loop capture. Composites Science and Technology, 2008. 68: p. 915-924.

14. Meredith, J., Coles SR, Powe R, Collings E, Cozien-Cazuc S, Weager B, Müssig J, Kirwan K, On the static and dynamic properties of flax and Cordenka epoxy composites. Composites Science and Technology, 2013. 80: p. 31-38.

15. Towo, A., Ansell MP, Fatigue evaluation and dynamic mecahnical thermal analysis of sisal fibrethermosetting resin composites. Composites Science and Technology, 2008. 68: p. 925-932.

16. Wind turbine generator systems - Part 23: Full-scale structural testing of rotor blades. 2002, British Standards Institution: London.

17. Highsmith, A., Reifsnider KL, Stiffness-reduction mechanisms in composite laminates, in Damage in Composite Materials, K. Reifsnider, Editor. 1982, ASTM: Baltimore, Maryland, USA.

18. Harris, B., ed. Fatigue in composites. 2003, Woodhead Publishing Limited: Cambridge, UK.

19. Shah, D., Schubel PJ, Clifford MJ, Licence P, Mechanical property characterization of aligned plant yarn reinforced thermoset matrix composites manufactured via vacuum infusion. PolymerPlastics Technology and Engineering, 2014. 53: p. 239-253.

20. Shah, D., Schubel PJ, Licence P, Clifford MJ Hydroxyethylcellulose surface treatment of natural fibres: the new 'twist' in yarn preparation and optimization for composites applicability. Journal of Materials Science, 2012. 47: p. 2700-2711.

21. Shah, D., Characterisation and optimisation of the mechanical performance of plant fibre composites for structural applications. 2013, University of Nottingham: Nottingham, UK. 
22. Shah, D., Schubel PJ, Clifford MJ, Licence P. Mechanical characterization of vacuum infused thermoset matrix composites reinforced with aligned hydroxyethylcellulose sized plant bast fibre yarns. in 4th International Conference on Sustainable Materials, Polymers and Composites. 6-7 July 2011. Birmingham, UK.

23. Shah, D., Schubel PJ, Clifford MJ, Licence P, The tensile behavior of off-axis loaded plant fiber composites: an insight on the non-linear stress-strain response. Polymer Composites, 2012. 33(9): p. 1494-1504.

24. Shah, D., Schubel PJ, Licence P, Clifford MJ, Determining the minimum, critical and maximum fibre content for twisted yarn reinforced plant fibre composites. Composites Science and Technology, 2012. 72: p. 1909-1917.

25. Baets, J., Plastria D, Ivens J, Verpoest I, Determination of the optimal flax fibre preparation for use in unidirectional flax-epoxy composites. Journal of Reinforced Plastics and Composites, 2014. 33(5): p. 493-502.

26. Kersani, M., Lomov SV, van Vuure AW, Bouabdallah A, Verpoest I, Damage in flax/epoxy quasiunidirectional woven laminates under quasi-static tension. Journal of Composite Materials, 2015. 49(4): p. 403-413.

27. Hughes, M., Carpenter J, Hill C, Deformation and fracture behaviour of flax fibre reinforced thermosetting polymer matrix composites. Journal of Materials Science, 2007. 42: p. 2499-2511.

28. Fibre-reinforced plastics - Determination of fatigue properties under cyclic loading conditions. 2003, British Standards Institution: London.

29. Liang, S., Gning, PB, Guillaumat, L, A comparative study of fatigue behaviour of flax/epoxy and glass/epoxy composites. Composites Science and Technology, 2012. 72(5): p. 535-543.

30. Andersons, J., Modniks J, Sparnins E, Modeling the nonlinear deformation of flax-fiber-reinforced polymer matrix laminates in active loading. Journal of Reinforced Plastics and Composites, 2015. 34(3): p. 248-256.

31. Harris, B., Engineering composite materials. 1999, London: The Institute of Materials.

32. Li, Y., Yuan BY, Nonlinear mechanical behavior of plant fiber reinforced composites. Journal of Biobased Materials and Bioenergy, 2014. 8(2): p. 240-245.

33. Placet, V., Cisse O, Boubakar ML, Nonlinear tensile behaviour of elementary hemp fibres. Part I: Investigation of the possible origins using repeated progressive loading with in situ microscopic observations. Composites: Part A, 2014. 56: p. 319-327.

34. Placet, V., Trivaudey F, Cisse O, Boubakar ML, What are the possible origins of the nonlinear tensile behaviour of hemp fibres?, in 19th International Conference on Composite Materials (ICCM-19). 2013: Montreal, Canada.

35. Spatz, H., Kohler L, Niklas KJ, Mechanical behaviour of plant tissues: composite materials or structures? The Journal of Experimental Biology, 1999. 202: p. 3269-3272.

36. Burgert, I., Fratzl P, Plants control the properties and actuation of their organs through the orientation of cellulose fibrils in their cell walls. Integrative and Comparative Biology, 2009. 49(1): p. 69-79.

37. Charlet, K., Eve S, Jernot JP, Gomina M, Breard J, Tensile deformation of a flax fiber. Procedia Engineering, 2009. 1: p. 233-236.

38. Bossuyt, V., PhD Thesis: Etude de la structure et des propriétés mécaniques de la fibre de lin. 1941, Université de Lille: Lille, France.

39. Charlet, K., Jernot JP, Moussa G, Baley C, Bizet L, Breard J. Morphology and mechanical behaviour of a natural composite: the flax fiber. in 16th International Conference on Composite Materials (ICCM-16). 2007. Kyoto, Japan.

40. Baley, C., Analysis of the flax fibres tensile behaviour and analysis of the tensile stiffness increase. Composites Part A: Applied Science and Manufacturing, 2002. 33: p. 939-948.

41. Hughes, M., Defects in natural fibres: their origin, characteristics and implications for natural fibre-reinforced composites. Journal of Materials Science, 2012. 47: p. 599-609.

42. Virk, A., Hall W, Summerscales J, Failure strain as the key design criterion for fracture of natural fibre composites. Composites Science and Technology, 2010. 70(6): p. 995-999.

43. Charlet, K., Jernot JP, Gomina M, Bizet L, Bréard J, Mechanical properties of flax fibers and of the derived unidirectional composites. Journal of Composite Materials, 2010. 44(24): p. 28872896. 
44. Keckes, J., Burgert I, Frühmann K, Müller M, Kölln K, Hamilton M, Burghammer M, Roth SV, Stanzl-Tschegg S, Fratzl P, Cell-wall recovery after irreversible deformation of wood. Nature Materials, 2003. 2: p. 810-814.

45. Page, D., El-Hosseiny F, The mechanical properties of single wood pulp fibres. Part VI. Fibril angle and the shape of the stress-strain curve. Journal of Pulp and Paper Science, 1983.

46. Altaner, C., Jarvis MC, Modelling polymer interactions of the 'molecular Velcro' type in wood under mechanical stress. Journal of Theoretical Biology, 2008. 253: p. 434-445.

47. Silvaa, FA, Chawla N, Filho RDT, An experimental investigation of the fatigue behavior of sisal fibers. Materials Science and Engineering A, 2009. 516: p. 90-95.

48. Bos, H., van den Oever MJA, Peters OCJJ, Tensile and compressive properties of flax fibres for natural fibre reinforced composites. Journal of Materials Science, 2002. 37: p. 1683-1692.

49. Bos, H., Molenveld K, Teunissen W, van Wingerde AM, van Delft DRV, Compressive behaviour of unidirectional flax fibre reinforced composites. Journal of Materials Science, 2004. 39: p. 21592168.

50. Shah, D., Natural fibre composites: Comprehensive Ashby-type materials selection charts. Materials \& Design, 2014. 62: p. 21-31. 